\title{
ATIVIDADES ESCOLARES ADEQUADAS PARA ATENDER AS NECESSIDADES EDUCATIVAS DOS ALUNOS DA EDUCAÇÃO DE JOVENS E ADULTOS
}

\author{
Renata Flávia França Silva
}

Marcel Pereira Pordeus ${ }^{2}$

RESUMO: Este artigo é um recorte de minha dissertação de mestrado apresentado à Universidad Interamericana. Deste fato, nesta pesquisa tratamos da educação de Jovens e Adultos como modalidade da Educação Básica, haja vista esta atender a um perfil de alunado bastante diversificado, e estes por estarem inseridos nessa modalidade diferenciada de educação, devem ter a oportunidade e acesso a uma boa qualificação para ter uma vida mais digna e humana. É fundamental entender a história, cultura e costumes desses alunos, para que assim se possa construir uma proposta pedagógica eficiente que seja capaz de atender as características específicas desses alunos, visto que mesmo tendo mais idade ou não, esses sujeitos continuam com total capacidade de aprendizado. No entanto, com o mundo evoluindo de forma célere, novas informações e conhecimentos que temos que assimilar a cada dia e, ainda, a mistura de diferentes alunos, de diferentes idades e capacidades na mesma sala de aula, acaba por contribuir com um processo de ensino mais demorado por parte de determinados aprendizes. Sabe-se que toda manifestação sobre a alfabetização e a educação para jovens e adultos está relacionada à decorrência da história de movimentos populares, para todos aqueles que não tiveram a oportunidade de completar seus estudos e/ou encontram-se a margem do processo educativo. Nesse sentido a escola tem um papel fundamental para que esses alunos possam superar e vencer as dificuldades para uma melhor qualidade de vida. Buscou-se com o estudo analisar as práticas pedagógicas adotadas para essa clientela, tendo em vista que são jovens e adultos que estão a margem do sistema regular, requerendo a construção de uma proposta pedagógica que atenda as reais necessidades desses educandos e conduza a aprendizagem de forma eficaz e significativa. Trata-se de uma pesquisa bibliográfica e de campo, com estudo exploratório de natureza qualitativa.

Palavras-chave: EJA. Atividades escolares. Necessidades educativas.

\section{INTRODUÇÃO}

A história da educação brasileira começa quando os padres jesuítas da Companhia de Jesus chegaram ao Brasil no período colonial, alfabetizavam os índios e filhos de

\footnotetext{
${ }^{\text {I }}$ Mestra em Ciências da Educação pela Universidad Interamericana. E-mail: naqynhaff@yahoo.com.br. ${ }^{2}$ Mestrando no programa de pós-graduação em Planejamento e Políticas Públicas da Universidade Estadual do Ceará (UECE). Graduando em Relações Públicas pela Universidade Federal de Santa Maria (UFSM). Graduado em Letras pela Universidade Federal do Ceará (UFC). E-mail: marcel.pordeus@aluno.uece.br.
} 
colonos para expandirem a fé católica em todo o continente. Para Sousa (2009), a influência religiosa dos jesuítas ainda pode ser encontrada em diversos setores da sociedade atual. Muitas instituições escolares do país, como também diversas instituições de ensino superior espalhadas por todo o território nacional, ainda são dirigidas ou sofrem profundas influência da Igreja Católica.

De acordo com Rosa (2011), outros fatos importantes transformaram o ensino no Brasil como a vinda da Família Real, a Independência e a Proclamação da República. Durante o período republicano, a educação recebeu novos incrementos a cada nova promulgação e/ou outorgação da Constituição Federal, uma vez que cada uma dessas Cartas Magnas definiam a importância da educação para o novo Estado de Direito estabelecido.

Com a chegada da família real e da coroa portuguesa ao Brasil, as instituições de educação do Brasil passaram por algumas transformações, dessa maneira diversos cursos de nível superior foram implementados no país. Uma transformação educacional que merece destaque foi instituição do Ato Adicional de 1834, que atribuiu às províncias, como medida de descentralização, a criação e a manutenção do ensino primário e secundário (ROMANELLI, 2002).

\begin{abstract}
O resultado foi que o ensino, sobretudo o secundário, acabou ficando nas mãos da iniciativa privada e o ensino primário foi relegado ao abandono, com pouquíssimas escolas, sobrevivendo à custa do sacrifício de alguns mestres escolas, que, destituídos de habilitação para o exercício de qualquer profissão rendosa, se viam na contingência de ensinar. O fato de a maioria dos colégios secundários estarem em mãos de particulares acentuou ainda mais o caráter classista e acadêmico do ensino, visto que apenas as famílias de altas posses podiam pagar a educação de seus filhos (ROMANELLI, 2002, p. 40).
\end{abstract}

Para o mesmo autor, na Constituição Republicana de I89i foi estabelecido o sistema dual de ensino, e foi oficializado o distanciamento entre a educação da elite do país, escolas secundárias acadêmicas e escolas superiores, e a educação do povo, escola primária e escola profissional. De acordo com Rosa (2011, p. I7 apud AZANHA, 1993, s/p), no ano de 1932 um grupo de 25 professores composto por homens e mulheres pertencentes a elite intelectual do país, lançaram um manifesto à população e ao governo que ficou conhecido como o "Manifesto dos Pioneiros da Educação Nova", que propunham a reconstrução educacional. 
[...] À luz dessas verdades e sob a inspiração de novos ideais de educação, é que se gerou, no Brasil, o movimento de reconstrução educacional, com que, reagindo contra o empirismo dominante, pretendeu um grupo de educadores, nestes últimos doze anos, transferir do terreno administrativo para os planos políticosociais a solução dos problemas escolares [...] (MANIFESTO DOS PIONEIROS DA EDUCAÇÃO NOVA, 1932, online).

Nesse contexto, os protagonistas desse manifesto declararam que: "Mas, com essa campanha, de que tivemos a iniciativa e assumimos a responsabilidade, e com a qual se incutira, por todas as formas, no magistério, o espírito novo, o gosto da crítica e do debate e a consciência da necessidade de um aperfeiçoamento constante, ainda não se podia considerar inteiramente aberto o caminho às grandes reformas educacionais [...]”.

[...] A questão primordial das finalidades da educação gira, pois, em torno de uma concepção da vida, de um ideal, a que devem conformar-se os educandos, e que uns consideram abstrato e absoluto, e outros, concreto e relativo, variável no tempo e no espaço. Mas, o exame, num longo olhar para o passado, da evolução da educação através das diferentes civilizações, nos ensina que o "conteúdo real desse ideal" variou sempre de acordo com a estrutura e as tendências sociais da época, extraindo a sua vitalidade, como a sua força inspiradora, da própria natureza da realidade social [...]" (MANIFESTO DOS PIONEIROS DA EDUCAÇÃO NOVA, 1932, online).

Rosa (20iI) enfatiza que esse documento teve grande repercussão, pois Constituição Brasileira de 1934 incluiu um artigo específico motivada por aquele manifesto. No Art. I50 que declarava ser competência da União "fixar o plano nacional de educação, compreensivo do ensino de todos os graus e ramos, comuns e especializados; e coordenar e fiscalizara sua execução, em todo o território do País" (BRASIL, 20II). Todas as constituições posteriores, com exceção da Carta de 1937, incorporaram, implícita ou explicitamente, a ideia de um Plano Nacional de Educação (PNE). Havia o consenso de que esse plano deveria ser fixado por lei. A ideia prosperou ao longo dos anos e nunca foi inteiramente abandonada.

O mesmo autor explica que o primeiro PNE surgiu no ano de 1962, criado quando já estava em vigor a primeira Lei de Diretrizes e Bases da Educação Nacional, Lei no 4.024, de 1961. Com a Constituição Federal de 1988, o debate a respeito de plano nacional de longo prazo, com força legislativa, que fosse capaz de dar estabilidade às ações do governo no setor educacional, foi novamente centro de debates. O Art. 2I4 contempla esta obrigatoriedade: 
Art. 214 ${ }^{\circ}$ A lei estabelecerá o plano nacional de educação, de duração decenal, com o objetivo de articular o sistema nacional de educação em regime de colaboração e definir diretrizes, objetivos, metas e estratégias de implementação para assegurar a manutenção e desenvolvimento do ensino em seus diversos níveis, etapas e modalidades por meio de ações integradas dos poderes públicos das diferentes esferas federativas que conduzam a: I - erradicação do analfabetismo; II universalização do atendimento escolar; III - melhoria da qualidade do ensino;[...]. (BRASIL, 2oIr, online).

O último Plano Nacional de Educação (PNE) foi promulgado em 20or, por meio da Lei no 10.172. com duração de dez anos - PNE 200I-20I0. Ficou estabelecido no Art. 2o que a partir da vigência dessa Lei, os Estados, o Distrito Federal e os Municípios deverão, com base no Plano Nacional de Educação, elaborar planos decenais correspondentes.

\section{O PROCESSO ENSINO E APRENDIZAGEM DOS SUJEITOS DA EDUCAÇÃO DE JOVENS E ADULTOS}

Os alunos da EJA são sujeitos que pararam de estudar por diversos motivos, retornam à sala de aula por vontade própria ou por "determinação" do mercado de trabalho

turbulento dos tempos atuais. Cada sujeito teve um motivo próprio para parar de estudar, e possui um motivo próprio para retornar. Nesse sentido, o currículo deve promover a esses indivíduos um processo de aprendizagem capaz de atender suas especificidades. Para Balsanell (2012), não há idade para aprender, mas um fator deve ser levado em conta: as pessoas que estão há muito tempo sem contato com os conteúdos do currículo escolar (tanto de ensino fundamental, quanto de ensino médio), ou que não possuem a cultura de lerem materiais diversificados sobre diferentes assuntos (ou não leem nada)), estão propícios a terem um raciocínio e aprendizado mais lento, requerendo respeito as diferenças para absorção do processo ensino e aprendizagem.

$\mathrm{Na}$ escola, o currículo - espaço em que se concretiza o processo educativo - pode ser visto como o instrumento central para a promoção da qualidade na educação. É por meio do currículo que as ações pedagógicas se desdobram nas escolas e nas salas de aula. É por meio do currículo que se busca alcançar as metas discutidas e definidas, coletivamente, para o trabalho pedagógico. O currículo corresponde, então, ao verdadeiro coração da escola. Daí a necessidade de permanentes discussões sobre o currículo, que nos permitam avançar na compreensão do processo curricular e das relações entre o conhecimento escolar, a sociedade, a cultura, a autoformação individual e o momento histórico em que estamos situados (MOREIRA, 2008, p s). 


\title{
2.I Saberes necessários a formação do docente da EJA
}

Grande parte dos alunos da modalidade de Educação de Jovens e Adultos (EJA) tem apresentado pouca ou nenhuma escolaridade anterior, mesmo assim eles detêm uma grande quantidade de conhecimentos elaborados ao longo de suas experiências. Segundo Freire (2000, p. 16):

\begin{abstract}
Ensinar exige respeito aos saberes dos educandos, por isso mesmo pensar certo coloca ao professor ou, mais amplamente, á escola, o dever de não só respeitar os saberes com que os educandos, sobretudo os das classes populares, chegam a ela, saberes socialmente construídos na prática comunitária, mas também a razão de ser de alguns desses saberes em relação com o ensino dos conteúdos. Interagir com esses saberes é estabelecer uma necessária “intimidade” entre os saberes curriculares fundamentais aos alunos e a experiência social que eles têm como indivíduos, de vida e trabalho.
\end{abstract}

Comenta-se muito que uma das causas do fracasso escolar é a incompetência do professor, isso devido à falta de recursos para que possa realizar seu trabalho. De acordo com Moretto (2002), o professor enfrenta três situações complexas a sua profissão: preparar a atividade educativa (planejar suas aulas), coordenar essa atividade (ministrar as aulas) e avaliar a aprendizagem (transformar as provas em momentos privilegiados de estudo e não em acertos de contas). A complexidade destas situações enfrentadas pelo professor em seu dia a dia, só poderão ser superadas com o apoio da organização escolar, sobretudo uma mudança de concepção da função social da escola, visando à educação para competências (PORDEUS, 2020).

A formação do professor de educação de jovens e adultos para Gadotti e Romão (2004), "deve levar em consideração os diversos estudos e pesquisas realizadas sobre as diferentes áreas de conhecimentos e suas gêneses, sobre o Construtivismo Interacionista e sobre Educação Popular”. A primeira teoria possui como seu elaborador Jean Piaget, a mesma possui o poder de prover informações sobre determinados conceitos que poderão ser utilizados e, até mesmo, empregados como base para que um educador possa fundamentar sua prática pedagógica e, dessa maneira, incentivar o aluno para o desenvolvimento cognitivo e para o processamento da aprendizagem de forma adequada. Há quatro fatores que Piaget considera essencial e até mesmo, responsável pelo desenvolvimento cognitivo da criança: I) Fator biológico: é um fator que está relacionado ao crescimento orgânico e a maturação do sistema nervoso. 2) Fator de experiências e de 
exercícios: este fator é obtido na ação da criança sobre os objetos. 3) Fator de interações sociais: é um fator que se desenvolve por meio da linguagem e da educação. 4) Fator de equilibração das ações: é um fator que está relacionado à questão da adaptação ao meio e/ou às situações. A segunda, a educação popular, social e comunitária não tem apenas caráter interdisciplinar - o trabalho social precisa ser integrado por equipes profissionais de diferentes áreas, com formação de nível médio, técnico ou superior - mas também tem um caráter intersetorial. Ao mesmo tempo, devido a sua enorme diversidade exigem-se conhecimentos e saberes específicos em cada caso. Não basta apenas boa vontade.

Ajala (20II) enfatiza que os jovens e adultos retornam à escola com a expectativa de conseguirem um emprego melhor, "de entenderem melhor as coisas", "de se expressarem melhor", "de serem gente", "de não dependerem sempre dos outros" percebe-se que as motivações desses alunos refletem o desejo sempre latente de ter uma melhor qualidade de vida. É na escola que esse desejo pode se transformar em realidade. É visível esta esperança nos olhos dos alunos da EJA. Neste contexto, o professor deve compreender que os alunos buscam a escola para se sentirem ativos, participativos e crescerem cultural, social e economicamente e não apenas pelo conteúdo já pronto para ser reproduzido. Gadotti e Romão (2004) argumentam que "os educadores precisam respeitar as condições culturais do jovem e do adulto. Eles precisam fazer o diagnóstico histórico-econômico do grupo ou comunidade onde irão trabalhar e estabelecer um canal de comunicação entre o saber técnico (erudito) e o saber popular” (AJALA, 20iI).

Para Sanches e Viana (20iI), a formação técnica faz parte da competência que o professor deve trazer na sua formação acadêmica, mas muitas vezes precisamos buscar na formação continuada um complemento para saber conduzir os ensinamentos dentro da complexidade dessa sociedade de conhecimento (EJA). A aprendizagem já é um processo envolvente por natureza, por ser um professor da EJA exige uma maior interação, compreensão e receptividade as expectativas dos alunos. Por isso, a disponibilidade se faz necessária porque muitas vezes nos deparamos mediando conflitos e restaurando a autoestima desses educandos.

O perfil do professor da EJA é muito importante para o sucesso do aluno que vê o professor como um modelo a seguir. Dentre as atribuições do professor está o compromisso em mostrar que a EJA é uma educação possível e capaz de mudar significativamente a vida de uma pessoa, permitindo a esta reescrever sua história e, também, compreender melhor o aluno e sua realidade diária, acreditando nas 
possibilidades do ser humano, buscando seu crescimento pessoal e profissional (SANCHES, VIANA, SILVA, 20II, p. 3).

A Lei de Diretrizes e Bases da Educação Nacional (LDBEN n. 9394/96), em seu artigo 37, prescreve que 'a Educação de Jovens e Adultos será destinada àqueles que não tiveram acesso ou continuidade de estudos no Ensino Fundamental e Médio na idade própria”. É característica dessa Modalidade educacional a diversidade do perfil dos educandos, com relação à idade, ao nível de escolarização em que se encontram, à situação socioeconômica e cultural, às ocupações e a motivação pela qual procuram a escola.

O papel fundamental da construção curricular para a formação dos educandos desta modalidade de ensino é fornecer subsídios para que se afirmem como sujeitos ativos, críticos, criativos e democráticos. Tendo em vista esta função, a educação deve voltar-se a uma formação na qual os educandos possam: aprender permanentemente; refletir de modo crítico; agir com responsabilidade individual e coletiva; participar do trabalho e da vida coletiva; comportar-se de forma solidária; acompanhar a dinamicidade das mudanças sociais; enfrentar problemas novos construindo soluções originais com agilidade e rapidez, a partir do uso metodologicamente adequado de conhecimentos científicos, tecnológicos e socioculturais (KUENZER, 2000).

Dessa forma, a proposta curricular para a educação de jovens e adultos enfatiza que cabe aos professores da EJA evidenciar possíveis mudanças que apontem para uma nova relação entre ciência, trabalho e cultura, por meio de uma base sólida de formação científica e histórica que ajude os educandos no seu desenvolvimento. Assim, conhecer significa a possibilidade de interferir socialmente (PORDEUS, 2020).

A escola é um dos espaços em que os educandos desenvolvem a capacidade de pensar, ler, interpretar e reinventar o seu mundo, por meio da atividade reflexiva. A ação da escola será de mediação entre o educando e os saberes, de forma que ele assimile conhecimentos como recursos de transformação de sua realidade (BRASIL, 2002). De acordo com o mesmo documento, no transcorrer do processo educativo, a autonomia intelectual do educando deve ser estimulada para que ele continue seus estudos, independentemente da educação formal. Cabe ao educador incentivar a busca constante pelo conhecimento produzido pela humanidade, presente em outras fontes de estudo ou pesquisa. Esta forma de estudo individual é necessária, quando se trata da administração 
do tempo de permanência desses educandos na escola e importante na construção da autonomia (BRASIL,2002).

\subsection{A educação de jovens e adultos na agenda internacional}

A história da EJA no Brasil passou por muitas transformações ao longo dos anos, desde as leis referentes a essa modalidade, como a necessidade de modificações nas estruturas de vários setores, entre elas, na metodologia. De acordo com morta Mota (2009), alguns fatos da história da EJA precisam ser destacados para um melhor entendimento do contexto no qual se insere. Parte das ações nesta área está restrita aos processos de alfabetização da população tem em vista dar conta das necessidades internas, enquanto perspectivas voltadas ao desenvolvimento, mas também das exigências externas instituídas por uma política internacional. A maioria das iniciativas de EJA, até então, surgiram com a participação do estado. A necessidade de prestar contas à comunidade internacional sobre os índices de analfabetismo fez com que o estado buscasse encontrar soluções imediatas para resolver o problema instalado e erradicar o analfabetismo (PORDEUS, 2020).

Segundo o Relatório Global sobre Aprendizagem e Educação de Adultos (UNESCO, 20Io), o direito universal a educação para todas as crianças, jovens e adultos é o princípio fundamental que sustenta todas as nossas iniciativas. A educação de adultos é mais importante do que nunca na era da globalização, caracterizada por mudanças rápidas, integração e avanços tecnológicos. A aprendizagem emancipa os adultos, dando-lhes conhecimentos e competências para melhorar suas vidas.

\footnotetext{
A educação de adultos desempenha um papel crucial na redução da pobreza, na melhoria da saúde e da nutrição e na promoção de práticas ambientais sustentáveis. Assim sendo, a consecução de todos os Objetivos de Desenvolvimento do Milênio exige programas de educação de adultos relevantes e de qualidade (UNESCO, 2oro, online).
}

O papel fundamental da educação de adultos no desenvolvimento da sociedade é reconhecido há muito tempo. Desde a Primeira Conferência Internacional sobre Educação de Adultos (CONFINTEA), em 1949, os Estados Membros da UNESCO têm se dedicado a garantir que os adultos possam exercer o direito fundamental à educação. As Conferências posteriores em Montreal (1960), Tóquio (1972), Paris (1985) e Hamburgo 
(1997) reafirmaram esse direito, e propuseram maneiras de torná-lo realidade. Em 1976, a Conferência Geral da UNESCO aprovou a Recomendação de Nairóbi para o Desenvolvimento da Educação de Adultos (UNESCO, 1976), que consagrou o compromisso dos governos de promover a educação de adultos como parte integrante do sistema educacional, numa perspectiva de aprendizagem ao longo da vida.

\section{CONCLUSÃO}

O desenvolvimento do presente estudo possibilitou uma análise das práticas pedagógicas adotadas para a educação de jovens e adultos, pois são grandes os desafios e as situações complexas vivenciadas pelo professor na educação de jovens e adultos, assim como também refletir sobre a elaboração de práticas pedagógicas específicas para atender as dificuldades desse público.

Tendo em vista os aspectos observados na pesquisa bibliográfica, sabe-se que o processo de alfabetização no Brasil é ainda extremamente deficiente. Existe no país um elevado número de pessoas analfabetas e de indivíduos que apresentam um perfil diferente das pessoas que não aprenderam a ler e escrever. As discussões e definições em torno de propostas teóricas e das diferentes concepções de alfabetização acompanham grandes lutas ideológicas e políticas, trazendo consequências pedagógicas sérias para o processo educativo dos sujeitos que buscam tardiamente a escolarização. Toda manifestação sobre a alfabetização e a educação para jovens e adultos está relacionada à decorrência da história de movimentos populares, para todos aqueles que não tiveram a oportunidade de completar seus estudos e/ou encontram-se a margem do processo educativo.

Outro fato histórico verificado e que fortaleceu essas lutas populares para cobrar do estado à responsabilização pela escolarização da EJA foi à criação da UNESCO, logo após o período da $2^{-}$Guerra Mundial, o movimento a favor da EJA ganha destaque internacional, em resposta aos movimentos populares e as deliberações da UNESCO, que o Estado aumenta as suas atribuições e responsabilidades para com a Educação de Jovens e Adultos. Dessa forma, foi em meio a campanhas e programas realizados no campo da Educação de Jovens e Adultos que surgiram o reconhecimento das características próprias dessa modalidade de ensino, o que para Haddad e Pierro (200o), acabou conduzindo a exigência de um tratamento específico nos planos pedagógicos e didáticos. Nesse período, 
a educação de adultos passou a ser reconhecida também como um poderoso instrumento de ação política. Finalmente foi lhe atribuída uma forte missão de resgate e valorização do saber popular, tornando a educação de adultos o motor de um movimento amplo de valorização da cultura popular.

$\mathrm{Na}$ literatura consultada foi relevante compreender que a educação pública não se enquadra como uma prioridade para os governantes, pois para os órgãos públicos a demanda na sociedade brasileira inviabiliza ter uma boa qualidade nesse setor. No entanto, Gadotti (2009) enfatiza que quando a escola pública era para poucos, era boa só para esses poucos. Agora que é de todos, principalmente para os mais pobres, ela precisa ser apropriada para esse novo público, ela deve ser de qualidade sociocultural. Isso significa investir nas condições que possibilitam essa nova qualidade que inclui transporte, saúde, alimentação, vestuário, cultura, esporte e lazer. É importante destacar a concepção ampliada da Educação de Jovens e Adultos no sentido de não se limitar apenas à escolarização, mas também reconhecer a educação como direito humano fundamental para a constituição de jovens e adultos autônomos, críticos e ativos frente à realidade em que vivem (BRASIL, 1999).

Há necessidade de uma maior divulgação sobre o objetivo da EJA junto de toda a comunidade escolar, pois para muitos alunos retornar à escola nessa modalidade de ensino, é apenas para aprender a ler, escrever e se alfabetizar. No entanto, esse contexto vai muito além do processo de alfabetizar-se, pois a escola é um dos espaços em que os educandos desenvolvem a capacidade de pensar, ler, interpretar e reinventar o seu mundo, por meio da atividade reflexiva. Os jovens e adultos excluídos do sistema regular devem ter a oportunidade de se qualificar e ter uma vida mais digna e humana, mesmo encontrando dificuldades de conciliar os estudos com as atividades profissionais da qual, na maioria dos casos provem sua subsistência.

Pela observação dos aspectos analisados, mesmo enfrentando inúmeras adversidades as escolas vêm procurando fazer a diferença, para melhorar o desempenho acadêmico dos alunos e assim poder garantir bons resultados para o sucesso escolar. Para que a escola possa de fato melhorar a oferta de ensino com qualidade, é preciso que todos os envolvidos no ambiente escolar possam ser uma unidade. 
Em vista dos argumentos apresentados nesse estudo, é fundamental entender que o perfil do educando da Educação de Jovens e Adultos requer conhecer a sua história, cultura e costumes para assim construir uma proposta pedagógica capaz de atender as características específicas desses alunos. É imprescindível que todos se conscientizem de que esses alunos estão afastados da sala de aula e seu ritmo de aprendizagem não é mais o mesmo. Essa compreensão contribuiu para mudanças no fazer pedagógico de minhas práticas em sala de aula, no sentido de buscar mais conhecimento sobre os anseios, as necessidades, os sentimentos dessas pessoas tão especiais e poder oferecer-lhes uma escolarização ampla, com mais qualidade para a realização pessoal e profissional.

\section{REFERÊNCIAS}

AJALA, Michelle Cristina. Aluno EJA: Motivos de abandono e retorno escolar na modalidade EJA e expectativas pós EJA em Santa Helena-PR. 20II. 45 f. Trabalho de conclusão de curso (Especialização em Educação Profissional Integrada) - Universidade Tecnológica Federal do Paraná, MEDIANEIRA, 2012. Disponível em: http://repositorio.roca.utfpr.edu.br/jspui/bitstream/I/r647/I/MD_PROEJA_2012_IV_I6.p df. Acesso em: or mar. 2021.

AZANHA, José Maria Pires. Políticas e planos de educação no Brasil. In: AZANHA, José Mário Pires. Cadernos de Pesquisa. Revista de estudos e pesquisas em educação. São Paulo: Fundação Carlos Chagas, 1993. p. 70-78. Disponível em: http://www.fcc.org.br/pesquisa/publicacoes/cp/arquivos/943.pdf. Acesso em: 03 mar. 2021.

BRASIL. Ministério da Educação. Decreto no 5.154, de 23 de julho de 2004. Regulamenta o § 20 do art. 36 e os arts. 39 e $4 \mathrm{I}$ da Lei no 9.394, de 20 de dezembro de 1996 , que estabelece as diretrizes e bases da educação nacional, e dá outras providências. Disponível em: http://www.planalto.gov.br/ccivil_03/_ato2004-2006/2004/decreto/D5154.htm. Acesso em: ro set. 2020 .

BRASIL. Decreto no. 2.208, de 17 de abril de 1997. Regulamenta o § 20 do art. 36 e os artigos 39 a 42 da Lei federal no. 9.394/96. Brasília, DF: i7 de abril de 1997.

BRASIL. Ministério da Educação. Decreto no 2.208, de 17 de abril de 1997. Revogado pelo Decreto $n^{\circ}$ 5.154, de 2004 Regulamenta o § 2 o do art. 36 e os arts. 39 a 42 da Lei no 9.394, de 
20 de dezembro de 1996, que estabelece as diretrizes e bases da educação nacional.

Disponível em: http://www.planalto.gov.br/ccivil_03/decreto/D2208.htm. Acesso em: ıo set. 2020.

BRASIL. Lei no 9.394, de 20 de dezembro de 1996. Institui as Diretrizes e Bases da Educação Nacional. Brasília, DF: 20 de dezembro de 1996.

FREIRE, Paulo. Pedagogia da Autonomia: Saberes Necessários à Prática Educativa São Paulo: Paz e Terra, 200o.

GADOTTI, Moacir; ROMÃO, José (Org.). Educação de jovens e adultos: teoria, prática e proposta. 3. ed. São Paulo: Cortez, 2004.

KUENZER, Acácia (org.). Ensino médio: Construindo uma proposta para os que vivem do trabalho. 5. ed. São Paulo: Cortez, 2005.

SANCHES, Jaqueline de Sá Rampazzo; VIANA. Edite Maria Sanches; SILVA, Rosângela da, Miranda. A identidade do aluno e do professor da EJA. Disponível em: https://www.plannetaeducacao.com.br/portal/. Acesso em: io fev. 202I.

MOREIRA, Valéria da Silva. Educação de Jovens e Adultos (EJA): uma reflexão sobre o abandono escolar. Disponível em http://bdm.unb.br/bitstream/10483/13165/1/2014_Val\%C3\%A9riadaSilvaMoreira.pdf. Acesso em: o5 fev. 2021.

MORETTO, Vasco P. Construtivismo, a produção do conhecimento em aula. 3. ed. Rio de Janeiro: DP\&A, 2002.

PORDEUS, Marcel Pereira. Cidadania, Direitos Humanos e Políticas Públicas para docentes na Educação de Jovens e Adultos (EJA). In: XX Encontro de Pós-Graduação e Pesquisa Unifor, 2020, Fortaleza. Anais dos Encontros Científicos 2020 - Universidade de Fortaleza (UNIFOR). Fortaleza: Universidade de Fortaleza (UNIFOR), 2020. v. 20. p. I-6.

ROMANELLI, Otaíza de Oliveira. História da educação no Brasil. Petrópolis: Vozes, 2002.

ROSA, Marcelo Pacheco da. Educação de qualidade no Brasil: um sonho possível?2orr. 69 f. 2oIr. Trabalho de Conclusão de Curso (Graduação) - Departamento de Estudos da Escola Superior de Guerra / Curso de Altos Estudos de Política e Estratégia (CAEPE), 201 . Disponível em http://www.esg.br/images/Monografias/20II/ROSA.pdf. Acesso em: ıo mar. 202I. 
SILVA, Hérica Fontes da. As causas da evasão escolar: um estudo de caso numa unidade de ensino da rede municipal de Itupiranga - Pará nos anos de 2013 e 2014. In: XII Congresso Nacional de Educação, 2015, PUCPR. Anais. Curitiba: EDUCERE, 2015. p. oI-13. Disponível em: http://educere.bruc.com.br/arquivo/pdf2015/20957_I1234.pdf. Acesso em: o8 jan. 2021.

SILVA, Marcos Jonatas Damasceno da; SILVA, Silmara Izabel da. Evasão escolar na educação de jovens e adultos: estudo de caso de uma escola pública no município de Acará, Pará. In: III Congresso Nacional de Educação - Cenários contemporâneos: a educação e suas multiplicidades., 2016. Anais. Natal: Editora Realize, 2017. p. or-o6. v. I. Disponível em:

http://www.editorarealize.com.br/revistas/conedu/trabalhos/TRABALHO_EVo56_MD 4_SAi2_ID7791_29072016192315.pdf. Acesso em: o6 fev. 2018.

SILVA, Raimundo Barbosa Filho, ARAÚJO, Ronaldo Marcos de Lima. Evasão e abandono escolar na educação básica no Brasil: fatores, causas e possíveis consequências. Disponível em:

http://revistaseletronicas.pucrs.br/ojs/index.php/porescrito/article/view/24527. Acesso em: 03 fev. 2021.

SOUSA, Rainer Gonçalves. A ação dos padres jesuítas no Brasil. Disponível em: http://mundoeducacao.bol.uol.com.br/historiadobrasil/os-jesuitas-no-brasil.htm. Acesso: 09 mar. 2021.

SOUSA, Lilia Ferreira Santana de. Causas e consequências da evasão escolar do EJA sob a perspectiva dos alunos da Serra do Abiá, Valença-BA. 2017. Disponível em https://even3storage.blob.core.windows.net/anais/77152.pdf. Acesso: Io jan. 2021.

UNESCO. Declaração de Hamburgo sobre a educação de adultos e plano de ação para o futuro. In: Conferência Internacional sobre a Educação de Adultos, 1997, Hamburgo. Anais. Hamburgo, Alemanha, 1997.

UNESCO. Relatório Global sobre Aprendizagem e Educação de Adultos. Brasília: UNESCO, 2010. 